\title{
A venue for progress
}

With this issue, Nature Medicine celebrates two years in print. In those two years biomedical research has affected the lives of real people and real patients be it by forcing a closer look at the ethics of population genome screening, furthering treatments (and some cures) for the diseases of our time or giving early warning of the risk of what used to be called lifestyle diseases such as some cancers and cardiovascular disorders. We notice a trend toward the publication of more and more ground-breaking human trials involving molecular approaches to diagnosis, treatment and databased prognosis. The once quite dull (but absolutely essential) phase I trial is evolving into an exciting venue in which to glimpse the future of preventive as well as therapeutic medicine.

At Nature Medicine, we feel privileged to be involved in contributing to human knowledge and the wellbeing of people everywhere. We have been stunned (and occasionally overwhelmed) by the sheer volume of first-class research that has been submitted as part of the nearly 3000 manuscripts we have received during the past two years. Of course, a monthly journal has only so much room, so we must necessarily decline to publish nearly $90 \%$ of these submissions. Despite the necessity of rejecting papers, we are, at heart, on our authors' side and know how much effort and hope lie behind every submitted manuscript. We thank all those who have stoically accepted our decision not to publish their work, as well as those who have contributed to our pages. We hope all parties will continue to trust us with their best work in the years to come.

Although we can claim some satisfaction with how the journal has developed, we are not resting on our laurels. We will introduce changes to the journal for 1997 - some minor and others less so. As molecular genetics and genome analysis have mushroomed, more researchers have developed appropriate and often lucrative links to the commercial side of research, development and drug discovery. This is proper because it is through the collaboration of academia, government and industry that research bears fruit, reaching the marketplace or bedside. However, with these collaborations come the inevitable questions about whether research can continue to be conducted with the detachment from its sponsors' interests that is necessary to ensure an open mind and unbiased conclusion. With stock prices rising and falling on the results of key research projects, it is naive to assume that attention from the commercial sector will not affect research. After all, institutions as well as individual scientists dream that business resources will support work that used to be funded by more generous grants or through money generated through the care of patients.

It is not Nature Medicine's aim to police research, nor do we believe that private or commercial sponsorship is damaging to science. Quite the contrary. But we do recognize the possibility that all results are not interpreted equally or in a vacuum. In 1997 we intend to publish guidelines for contributors that may well follow the principle that disclosure of all ties to financial, political or advocacy parties is honest and worthwhile and enables readers to judge for themselves the importance and possible ramifications of such relationships. We also invite your opinion on this issue.

Nature Medicine has benefited throughout its young life from readers' feedback. With this in mind, we have decided to separate Commentary and Review into two distinct sections. The author of a Commentary is invited, within the context of acquired wisdom and acknowledged expertise, to discuss his or her personal beliefs and biases on an issue, furthering the debate about science policy, funding, ethics and related issues. Authors of Reviews, on the other hand, are explicitly asked to provide as objective an assessment of their chosen subject as is humanly possible. Here we hope to print brief, lucid, and insightful reviews of important new data in all areas of biomedical research with a view to enlightening the reader and fostering better science through cross-fertilization of ideas and concepts from one discipline to another. Although there will always be some common ground, the Commentary section will develop ideas and proposals that offer no apology for their creativity and opinion, whereas Reviews will concentrate more on fact, explanation and wise interpretation.

Other planned changes are intended to improve the accessibility and appearance of the journal. Despite the increased importance of electronic media, we have not lost sight of the great attraction for the printed word. For many, the sensation of thumbing through real pages will never be replaced by scrolling through virtual pages. For them and all our readers, we have looked carefully at making the journal easier and more satisfying to read. Nevertheless, Nature Medicine is investing in electronic communications and publishing, and 1997 will see significant developments in that area.

- Adrian J. Ivinson and Barbara J. Culliton 